\title{
Importance of Physical Fitness during Covid-19 Era
}

\author{
Mohd Sarfraz, Parag Rawal, Chirag Sharma
}

\begin{abstract}
Contemplating healthy exercise and well-being are important for everyone. The point of the ebb and flow study was to examine the effect of thinking on living well in real life and in sound behaviour in humans. The benefits of exercise and exercise have been demonstrated throughout life. We are meant to walk and many of our body systems work better when we are physically active. By controlling depressive symptoms, some studies show that high levels of aerobic activity can be associated with a significant reduction in depressive symptoms. Consider engaging in one or two daily exercises that include short periods (30-90 seconds) of high intensity. For some, this can be achieved by exercising in their homes including jumping jugs, mountain climbers, and a series of strength exercises (i.e. standing squats, push-ups, sit-ups). For others, the use of home exercise equipment such as treadmills, elliptical machines, and stationary bicycles may be helpful.It will help people to improve their physical fitness and fitness programs.

Keywords: Physical Fitness, Awareness, Exercise.
\end{abstract}

\section{INTRODUCTION}

Ordinary life is a piece of great welfare. It means having a strong body mass as a capacity to perform active activities without fatigue without a problem. A healthy lifestyle is the opposite of this kind of well-being. It means how well one can control the precise levels in a game. Real life is an important condition for well-being and prosperity, chronic illness, and inequality. Miss of extra especially, the ability to do parts of sports, activities and daily development. Real-life is often ended with proper diet, normal diversions of fire, real thinking, and adequate rest. It has been proven that the development of the basic life of diversification and adherence to entertainment. Thinking about physical activity can also reduce the risk of injury, just as it improves real health, weight management, mental strength, and personal satisfaction. Without knowing the real welfare, people have not yet collected the recommended level of active work. The community has limited resources to advance real work such as the absence of planning, preparation, metalworking, and short-term investigations. Most people who move to the ground are strong enough to participate in vibration, yet they do not pay attention to the real basis of active work. Ignorance drives them to a continuing problem and difficulty. The emergence of a real work perspective puts you at risk. We call them power and not their part in the performance.

Manuscript received on April 28, 2021.

Revised Manuscript received on May 22, 2021.

Manuscript published on May 30, 2021.

* Correspondence Author

Mohd Sarfraz*, B.Tech, Computer Science and Engineering, Lovely Professional University, Punjab, India Email: mohdsarfraz679@gmail.com

Parag Rawal, B.Tech, Computer Science and Engineering, Lovely Professional University, Punjab, India

Chirag Sharma, Assistant Professor, Department of Computer Science and Engineering, Lovely Professional University, Punjab, India

(C) The Authors. Published by Blue Eyes Intelligence Engineering and Sciences Publication (BEIESP). This is an open access article under the CC BY-NC-ND license (http://creativecommons.org/licenses/by-nc-nd/4.0/)
People with a low level of understanding of the action are much more grounded than a real strong crowd. It is unexpected and has a variety of features that are not difficult to come by. Knowing your physical composition, extinction, profitability, and environment, and so on, is important in specific sports. Contemplation is the first step in counselling. Exercise puts them at risk. We call them operating automatically and not in their part in use. People with a low level of professionalism are healthier than ignorant bodybuilders. It is complex and varied and easy to access. Knowing your body, problem, benefits, and spirit, etc., are the prerequisites for a particular sport. Awareness is the first step in counselling. The advantages of exercises are listed below:

a. Physical Benefits of Exercise: Heart disease, pneumonia, and diabetes are some of the most common chronic illnesses that Americans face. Here are some ways exercise can prevent or reduce common health problems associated with these conditions.

b. Exercise decreases blood pressure. Regular physical activity helps the heart to pump blood more efficiently with less effort. A strong and effective heart lowers blood pressure, which in turn lowers blood pressure.

c. Exercise improves insulin sensitivity. With regular exercise, the cells in the body become more sensitive to insulin, which means they can use glucose more efficiently and thus help keep it in good condition.

d. Exercise lowers cholesterol. Cholesterol is carried in the body by high-density lipoproteins ("good cholesterol") or low-density lipoproteins ("bad cholesterol"). Exercise regularly increases good cholesterol and decreases bad cholesterol in the body.

e. Exercise improves sleep quality and duration by reducing symptoms of arousal and anxiety.

f. Exercise helps in weight management by using energy (calories) as fuel. Exercise can also promote weight gain and increase muscle mass.

g. Exercise promotes bone growth and improves bone performance, strength, and size. Exercise can prevent serious health-related problems such as osteoporosis, osteopenia, and bone fractures.

h. Exercise strengthens and enlarges muscle mass in a process called cell hypertrophy (enlargement of muscle cells). Regular exercise results in enlarged muscle cells that can show greater strength. If the tissue is used/trained over and over again, we can get more muscle cells to be used to strengthen the muscles.

It was once understood that well-offended young people show mental development taking realistic planning for prosperity, yet no end can be seen that includes the consequences of great boring prosperity and other clinical issues.

Published By:

Blue Eyes Intelligence Engineering 
The results confirmed that it was extremely difficult for ordinary social workers to show extended details about the length of interest aside. I have shown you that bigger part people find themselves busy with redirecting for twenty to sixty minutes each day, three days consistently, remembering the energy level for example seventy to very high. Pulse will collect at any rate specific conditions related to prosperity associated with respiratory well-being and high heart rate of actual performance. Beneficiaries who show low respiratory health may be able to receive moderate news in very small improvements; while greater energy and time to operate consistently may be required to further some of the ambitions for change.

Work at Home: In March 2020, the World Health Organization (WHO) announced the COVID-19 epidemic, and soon, many countries around the world began declaring locks and strict social protection, respiratory hygiene and hand sanitation agreements to control the world as soon as possible.

While many essential service providers have had to keep going to their workplaces on a daily basis, many other offices have transferred the homework of all staff. This means that all kinds of professionals, from IT professionals to journalists and filmmakers, move from organized workplaces to the suburbs of their homes. For nine months or so, offices that can function effectively without the need for the presence of their staff choose to continue doing so. Serious and long-term changes can have a profound effect on all affected professionals around the world. Force, or increase oxygen uptake (VO2max). VO2max testing with standard print demonstrations or detailed pre-tests or explicit tests that prevent cardio intensity independent of memory or floral control. Actual work is limited to social research. This study provided each segment with a specific effort towards detailed meetings of regular/energetic effort lasting more than 20 minutes in the most recent period of the month. The actual movement rate at 12 weeks was $24 \%$ higher than the total number of outstanding management interventions, which for the first time could not be considered as basically measurable.

New General: Apply the following work guidelines for the American College of Sports Medicine (ACSM). Always consult your doctor or health care provider before starting a new exercise program to determine if it is right for you.

- Healthy adults aged 18-65 should participate in at least 30 minutes of exercise on average five days a week OR 150 minutes of exercise per week

- Healthy adults aged 18-65 should perform strenuous or endurance exercises that work on all major muscle groups at least two days a week.

- Healthy adults aged 18-65 should exercise moderately and moderately two to three days a week.

Death: As of March 15, 2021, an outbreak of corona virus (COVID-19) had spread to six continents, and more than 2.6 million people had died after contracting a respiratory infection as shown in Fig. [1].

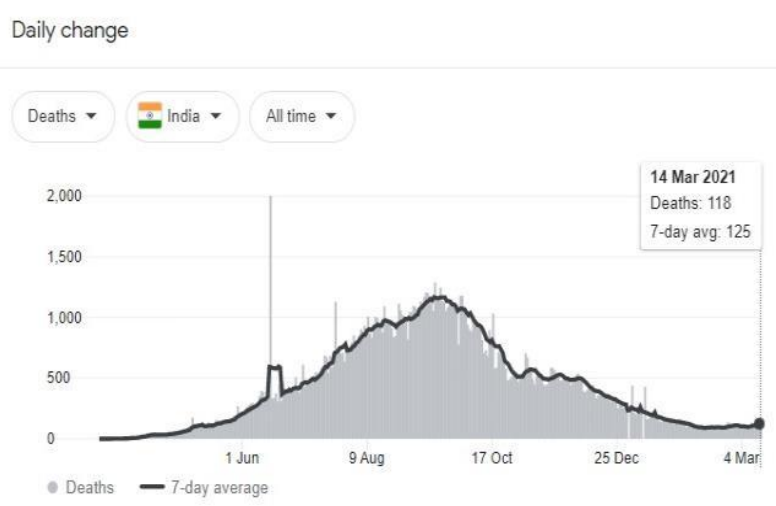

Fig.1: Showing deaths from COVID-19.

Covid-19 Outcome: The COVID-19 epidemic has led to significant global health losses and poses an unprecedented challenge to public health, food systems and the world of work. The economic and social disruption caused by the epidemic is devastating: tens of millions of people are at risk of falling into extreme poverty, and the number of undernourished people, currently estimated at 690 million, could rise to 132 million by the end of the year.

Millions of businesses are facing an existing threat. About half of the world's 3.3 billion workers are at risk of losing their lives. Workers in the informal economy are at greater risk because the majority lacks social protection and access to quality health care and has lost access to productive assets. Without ways to earn money during lockdowns, many cannot support themselves and their families. For many, no income means no food, or, at least, little or no nutritious food.

Millions of agricultural workers - both working and self-employed - while feeding the world, live in high levels of working poverty, malnutrition and poor health, and suffer from insecurity and protection of workers and other forms of harassment. With low and unusual incomes and a lack of social support, many of they are encouraged to continue working, often in unsafe conditions, thus exposing themselves and their families to further risk. In addition, when they experience a loss of income, they may resort to unscrupulous tactics, such as the sale of property pressure, food loans, or child labor. Migrant agricultural workers are at high risk, as they face risks in their relocation, working conditions and lives and are struggling to access support services provided by governments. Ensuring the safety and health of all agricultural food workers - from leading producers to those involved in food processing, transportation and marketing, including street food retailers - and income and protection, will be critical to saving lives and protecting public health, livelihoods, and food security.

\section{What are they missing? \\ LOSS OF WORKS AND LIVES WITHOUT PUBLIC SAFETY NETWORKS:}

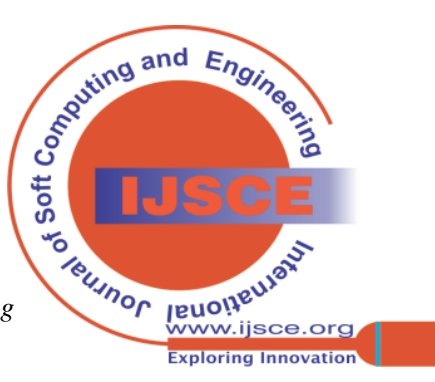


Although job losses and wages are widespread under the COVID-related economic constraints, women and girls remain at high risk. Indeed, 92 percent of working African women are in the informal economy, leaving them without job security or benefits. Under closure measures and out of public safety nets, unscrupulous employees have had to face the difficult decision of whether to violate the closure, risk their lives and legal consequences, or not earn money. However, while the COVID-19 virus leaves millions of African women and children without jobs, food, and health care, the fact is that this was a pre-epidemic situation. Creating an inclusive social policy and protecting vulnerable families during and after the crisis will go a long way in protecting vulnerable women and families. At the same time, women's investment in small and medium enterprises will better protect the financial and economic well-being of families and the economy.

\section{LITERATURE SURVEY}

The COVID-19 pandemic is a gigantic worldwide wellbeing emergency and quickly spreading pandemic of late occasions. When contrasted with the previous the global epidemic you have seen, the current COVID-19 epidemic is currently at the top of the list in terms of all inclusion. This is the first time around the world it is influenced simultaneously and is hit hard by the time limit. Initially, the death toll from COVID-19 was almost 2\%, now it has increased to about 4-6\% (WHO). The details do not seem too good to be true, but the sheer number of cases and the sheer number of cases increasingly complicate matters. The dramatic progress in COVID-19 cases has led to the division of billions of people and total locks. Corona virus has influenced the presence of almost everyone in the world. The difference between a close home or professional life is limited due to homework guidelines, and people's lives revolve around both because of the lock. More and more people are thinking about the important concerns at home, namely, the importance of their well-being and well-being. While forcing locks or social isolation has become one of the most widely used measures in the world to curb the rapid spread of COVID-19, there are also extreme consequences. Mental prosperity, psychosocial and passionate issues just as on rest quality, and work status. Declaration of an unexpected lockdown, all things considered, and exercises, with the exception of few fundamental administrations, by the specialists has brought about an extreme change in the way of life of influenced individuals and has seriously hindered their emotional wellness, which has been showed as expanded uneasiness, stress, and sadness. The abrupt changes in individuals' way of life incorporate, however are not restricted to, proactive tasks and exercise have revealed that COVID-19 home imprisonment has brought about an abatement in all degrees of proactive tasks and about $28 \%$ expansion in day by day sitting time just as expansion in unfortunate example of food utilization. Comparative outcomes are accounted for by different analysts also. Albeit these unexpected changes have impacted each person, numerous individuals who were consistently following their wellness exercises in centre, or in the ground, or different spots before the lockdown have been influenced strongly.
The result of the focus on well-being and recreation has prevented people from staying at home, disrupting their daily schedules and disrupting their health careers. While the pressure to stay home longer represents the test of the coherence of real well-being, knowledge of active functional impairment, the dangers of social networking, and the weaknesses that lead to an increase in psychological and physical health problems. Track that psychiatric disorders occur in adults as they become accustomed to a healthy lifestyle in line with the fear of getting infected with COVID-19. However, robust adaptation programs, intellectual property, and regular exercise can help manage such well-related social problems during the COVID-19 epidemic. It is imperative to take note of that proactive tasks (PA) and exercise keep up physical and mental wellbeing as well as assist our body with reacting to the negative outcomes of a few sicknesses like diabetes, hypertension, cardiovascular illnesses, and respiratory infections. In a new survey of 31 distributed investigations, presumed that actual latency because of current pandemic limitations is a significant general medical problem that is an unmistakable danger factor for diminished future and numerous actual medical conditions. Exercise seems to retain some of the real strength (respiratory, circulatory, strong, nervous, and skeletal structures) that is flawless and elevates the various structures (endocrine structures, related, unprotected, or kidney) that are important in combating any known or hidden danger of our own. However, when social development tests, for example, sports and general rec institution activities are not available in this epidemic, it is very difficult for people to meet all WHO rules (150 min moderate to mild PA or 75 min increased PA each week or a combination of both. Among these epidemic-related limitations (home issues with closed gym facilities, parks, and wellness centres), how people adapt and find ways to continue their real life remains an important question. COVID-19 has also given various researchers to explore their research in the field of cryptography. Sharma $[10,11]$ added hyperchaotic encryption to encrypt watermark before embedding to selected frame of video. Hyperchaotic encryption provided good results against different attacks.

\section{METHODOLOGY}

Gaining a rich and comprehensive understanding of the interactions in people's lives during the disease and their efforts to maintain a healthy lifestyle, an independent approach to research was adopted. We used Interpretive Phenomenological Analysis (IPA) to dig into members 'understanding and provide a closer picture of special members' meetings at a set time.

\section{Participants:}

A sample of 20 members was selected from the survey. The reason based on the rating of this test method was used to identify and select members.

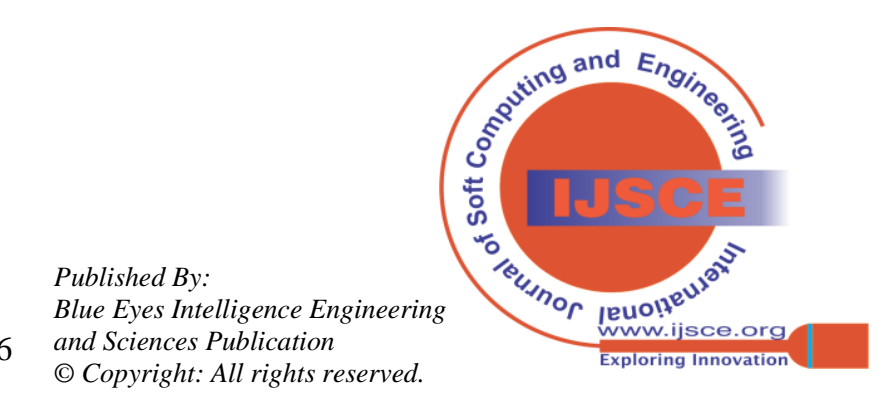


Initially we reached out to the owners / advisors of the rec centre and checked to see if they were willing to help us with the test. Once we have agreed, we have asked them to give us the tricks of their ordinary people who work in the gym and do social work in any event the year before the forced closure. During the construction of the rundown, nearby members were telephoned, briefed on the purpose of the test, and agreed to take part. Individuals who agreed to be considered for the study were then asked a few questions based on selected models for inclusion and rejection in the examination. Based on this data, those members met the criteria for consideration (i.e., people who continued to exercise in their homes or communities and followed the strict measures of home arrest during the COVID-19 epidemic and subsequent closure)as shown in the Fig. 2 and Table 1.

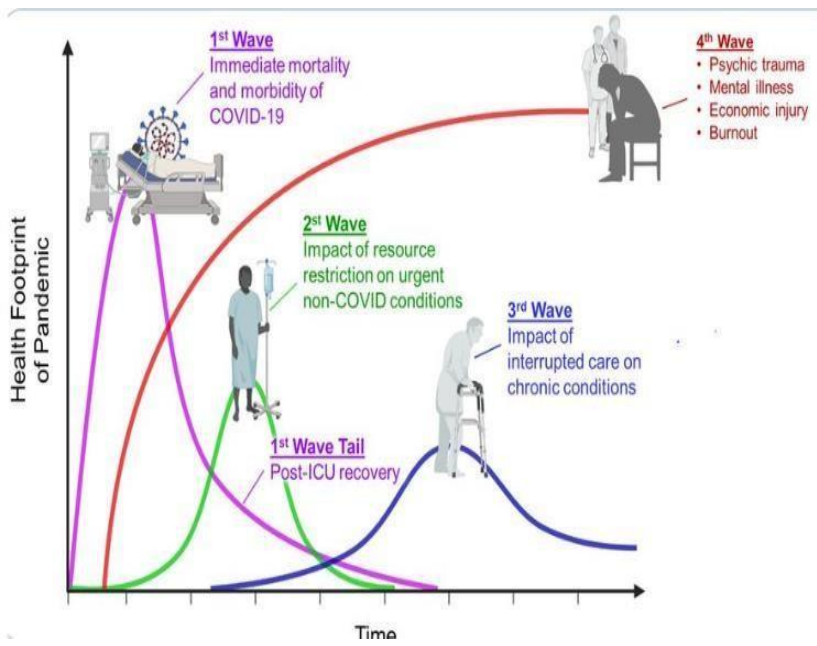

Fig.2 : Showing the impact of COVID-19 waves by the time passes.

\section{Participants Engaging in Physical Activity:}

The participants who engaged in physical activity during the lockdown, the reasons for devotion to physical activity were reported as weight loss, recreational and general fitness. The quality of sleep as perceived by the participants in the study was rated at good (38.2\%) \& excellent (34.3\%). As shown in the Figure 3.The quality of life as perceived by the participants was good (49.19\%) and average (31.96\%).

\section{Participants not Engaging in Physical Activity:}

The factors for not devoting to physical activity were reported as laziness, disturbed schedule and sleep and work duties as shown in the Figure 4.

\section{Inclusion and Exclusion Criteria for the Participants}

The participants meeting the following criteria were included in the study:

- Individuals aged 18 years or older.

- People with no unknown history of physical or potentially mental ailment.

- Individuals who were doing standard rec centre exercise throughout the previous a half year or more for in any event 45 min every prior day COVID-19.

- Individuals who were totally reliant on rec centre exercise for their actual wellness.

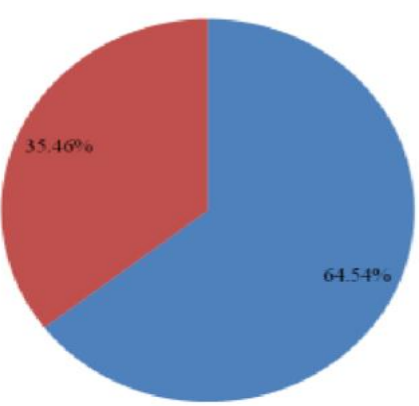

- Engaging in $\mathrm{PA}$ mot Enagaging in

Fig 3: Pie chart - showing the people who engage and not engage in Physical activity

Table 1: Data of the individuals who were proceeding for physical wellness.

\begin{tabular}{|l|l|l|}
\hline Variable & $\begin{array}{l}\text { Variable } \\
\text { levels }\end{array}$ & Characteristics \\
\hline Gender & Male & 20 \\
\cline { 2 - 3 } & Female & 2 \\
\hline Age(in years) & Minimum age & 19 \\
\cline { 2 - 3 } & Maximum age & 34 \\
\cline { 2 - 3 } & Mean age & 26.5 \\
\hline Occupations & Student & 6 \\
\cline { 2 - 3 } & Homemakers & 1 \\
\cline { 2 - 3 } & $\begin{array}{l}\text { Working } \\
\text { professionals }\end{array}$ & 11 \\
\cline { 2 - 3 } & Entrepreneur & 2 \\
\cline { 2 - 3 } & Unemployed & 4 \\
\hline Marital status & Single & 19 \\
\cline { 2 - 3 } & Married & 2 \\
\cline { 2 - 3 } & Separated & 1 \\
\hline Living status & Living alone & 7 \\
\cline { 2 - 3 } & $\begin{array}{l}\text { Living with } \\
\text { family }\end{array}$ & 15 \\
\hline \multirow{5}{*}{$\begin{array}{l}\text { Socioeconomic } \\
\text { status }\end{array}$} & Middle class & 18 \\
\cline { 2 - 3 } & Higher class & 4 \\
\hline
\end{tabular}

Blue Eyes Intelligence Engineering and Sciences Publication 


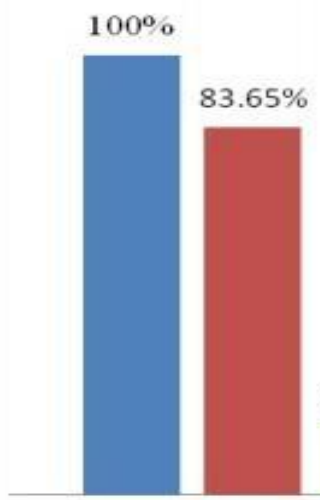

Regularly

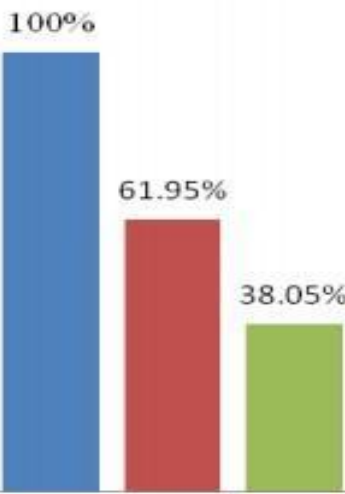

Ocassionally
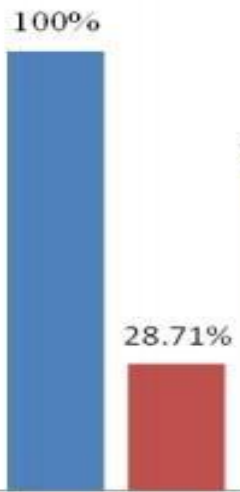

$71.29 \%$

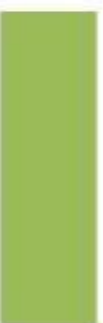

Never

Fig 4 : Graph for showing the percentage of Physical activity level before lockdown and the persons who are engaging and not engaging on the basis of regularly, occasionally, and never participated in Physical activity.

Table 2: Details of the participants who engage in physical activity during covid-19.

\begin{tabular}{|c|c|c|c|}
\hline & $\begin{array}{l}\text { Total } \\
\text { population }\end{array}$ & $\begin{array}{l}\text { Exercising } \\
\text { population }\end{array}$ & $\begin{array}{l}\text { Non- } \\
\text { Exercising } \\
\text { population }\end{array}$ \\
\hline & $(\mathrm{N}=1,110)$ & $(\mathrm{n} 1=710)$ & $(\mathrm{n} 2=400)$ \\
\hline \multicolumn{4}{|l|}{ Age } \\
\hline 18-29 & 601 & 382 & 219 \\
\hline $30-39$ & 194 & 132 & 62 \\
\hline $40-49$ & 128 & 94 & 34 \\
\hline $50-59$ & 149 & 75 & 74 \\
\hline $\begin{array}{ll}60 & \text { and } \\
\text { above } & \end{array}$ & 38 & 27 & 11 \\
\hline \multicolumn{4}{|l|}{ Gender } \\
\hline Male & 443 & 301 & 142 \\
\hline Female & 667 & 409 & 258 \\
\hline \multicolumn{4}{|l|}{ Work Profile } \\
\hline $\begin{array}{l}\text { Sedentary } \\
\text { work }\end{array}$ & 511 & 300 & 211 \\
\hline Light work & 459 & 311 & 148 \\
\hline Medium & 127 & 90 & 37 \\
\hline Heavy work & 13 & 9 & 4 \\
\hline \multicolumn{4}{|l|}{ Sitting hours } \\
\hline $\begin{array}{l}\text { Greater } \\
\text { than } 7\end{array}$ & 371 & 212 & 159 \\
\hline 5 to 7 hours & 351 & 221 & 130 \\
\hline 3 to 5 hours & 375 & 269 & 106 \\
\hline 1 to 3 hours & 13 & 8 & 5 \\
\hline
\end{tabular}

\section{PROPOSED WORK}

Our main aim is to support the sports for all the people so that they become fit by actively participating in the sports and by the help of that they can overcome almost all the disease. Anyone can register by entering details to view their records and dashboard. In this we collect name, email, address, school name, date of birth, mobile number, aadhar number. In this project we are using HTML, CSS, JavaScript for the frontend and PHP, MySQL for the backend and database connectivity.

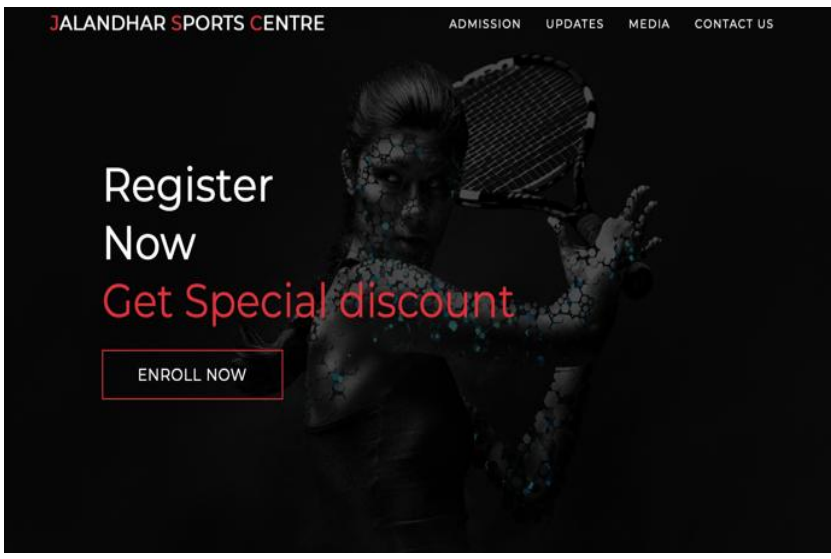

Description: This is our project homepage. There is the button for enrolling to participate.

\section{ALANDHAR SPORTS CENTRE \\ ADMISSION UPDATES MEDIA CONTACT US}

\section{O COVID SAFETY PROTOCOLS}

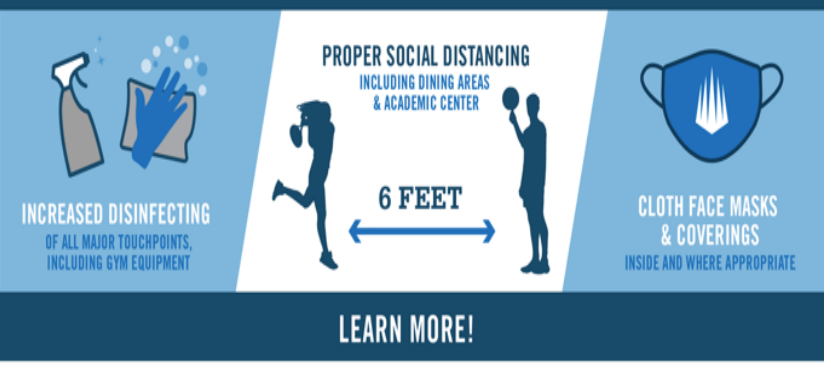

Description 2: This is also on our homepage to follow the protocol in this pandemic. If anyone click on this, it will open the WHO portal.

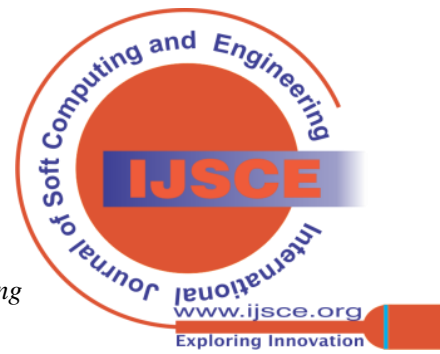




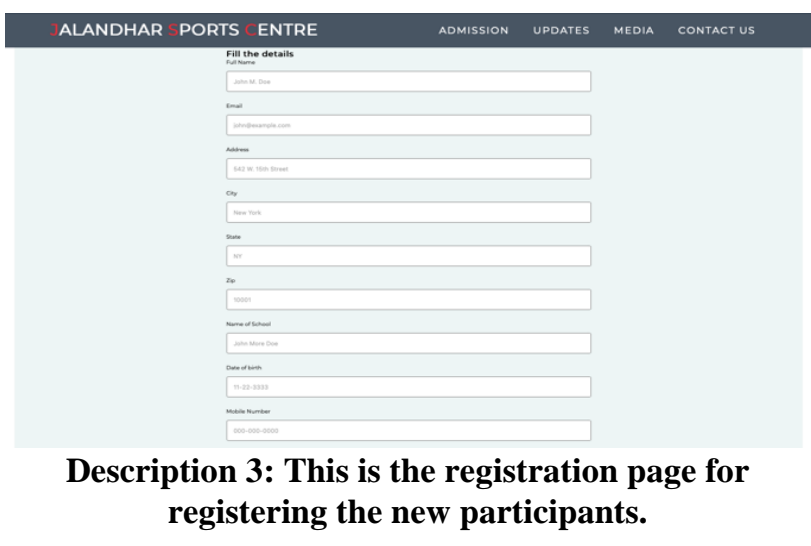

ALANDHAR ENNIS CADAMY

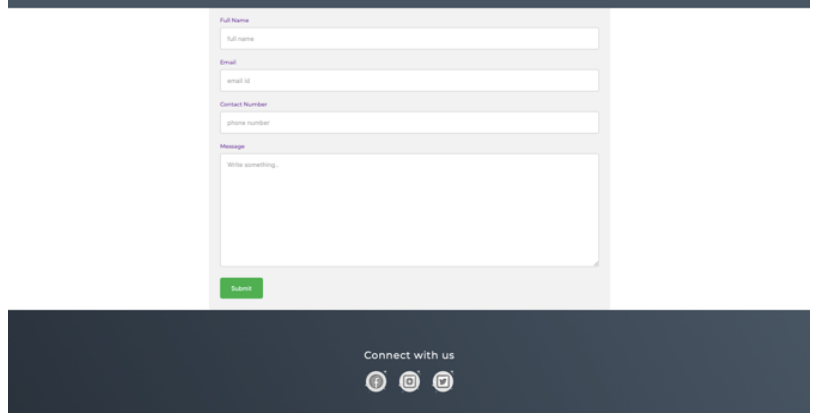

Description 3: This is the contact page for any query related to the academy.

\section{DISCUSSION AND CONCLUSIONS}

The point of this study was to inspect the insights about wellness and to dissect the effect of wellness mindfulness on actual wellness. The COVID-19 pandemic has acquired significant disturbance the existence of each person across the globe. It has hampered the everyday exercises of practically all people including the individuals who rely upon rec centres for their actual wellness schedule. The current investigation was led with people for whom going to the exercise centre was a normal movement in order to investigate their encounters regarding their impression of the pandemic circumstance and their methods of adapting to COVID-19-actuated vulnerabilities and medical problems. It was reasoned that wellness mindfulness had huge and constructive outcomes on actual wellness and solid propensities. The acquired outcomes showed that most individuals were uninformed about actually action. It will assist individuals with improving their actual wellness and exercise programs.

\section{SUGGESTIONS}

Further examination might be done to inspect the impacts of mindfulness on an enormous example for the two sexes. This examination may likewise use to analyse the Study at public and worldwide level. Appropriate mindfulness projects might be presented at public level. The effect of wellness mindfulness is positive and critical towards wellbeing and wellness; in this manner, the social exercises may likewise be presented with actual wellness mindfulness.

\section{REFERENCES}

1. Babey SH, Brown ER, Hastert TA. Access to safe parks helps increase physical activity among teenagers. Policy Brief/UCLA Centre for Health Policy Research. 2005;(PB2005-10)

2. Folkins, C. H., \& Sime, W. E. (1981). Physical fitness training and mental health. American psychologist, 36(4), 373.

3. Malina, R. M. (1996). Tracking of physical activity and physical fitness across the lifespan. Research quarterly for exercise and sport, 67(sup3), S-48.

4. Twisk JW, Kemper HC, van Mechelen W. Prediction of cardiovascular disease risk factors later in life by physical activity and physical fitness in youth: general comments and conclusions. Int J Sports Med 2002; 23: S44-S49.

5. Minifee, M., \& McAuley, E. (1998). An Attributional Perspective on African American Adults' Exercise Behavior1. Journal of Applied Social Psychology, 28(10), 924-936.

6. World Health Organization. Move for Health Day and Global Physical Activity Questionnaire.

7. Sirgy, M. J., Reilly, N. P., Wu, J., and Efraty, D. (2008). Healthcare model: According to the research agenda linking performance quality (QWL) and health quality (QOL) programs. Research Featured on Quality of Life, 3 (3), 181-202.Leith, L. M. (1992). Behaviour modification and exercise adherence: A literature review. Journal of Sport Behaviour, 15(1), 60.

8. Weiss TW, Slater CH, Green LW, Kennedy VC, Albright DL, Wun CC. The Validity of Single-Item Self-Assessment Questions as Measures of Adult Physical Activity. J Clin Epidemiol 43(11):11239, 1990.

9. McArdle, W. D., Katch, F. I., \& Katch, V. L. (1996). Use of energy for household chores, work, recreation and sports.

10. C. Sharma, A. Bagga, B.Singh, M.Shabaz, "A Novel Optimized Graph Based Transform Watermarking Technique to Address Security Issues in Real Time Application", Mathematical Problems in Engineering,2021.

11. C. Sharma, A. Bagga , R. Sobti ,T. Lohani, M.Shabaz, "A Secured Frame Selection Based Video Watermarking Technique to Address Quality Loss of Data: Combining Graph Based Transform, Singular Valued Decomposition, and Hyperchaotic Encryption", Security and Communication Network,2021.

\section{AUTHORS PROFILE}

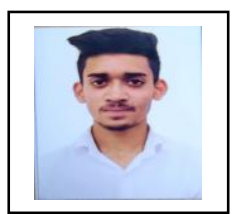

Mohd Sarfraz, is pursuing B.TECH CSE from Lovely Professional University and did some of the projects like daily expense tracker website, blogging website, scientific calculator using python, smart irrigation system in electronics and communication and hotel management system website. He has also done the certifications in fundamental of $\mathrm{C}$, ReactJS and also EFSET certification in English.

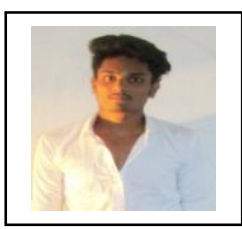

Parag Rawal, is pursuing B.TECH CSE from Lovely Professional University. He did several project like online cab rental store, library, restaurant website using programming languages. He also did some certification of courses like AWS fundaments, Java Programming Language, C++ object oriented programming, basic ReactJS.

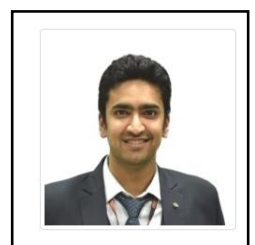

Chirag Sharma, has completed M.TECH 2012 and submitted PHD thesis in 2021 from Lovely Professional University. His research interests include security, image processing, data mining, data analytics, gait recognition, edge detection and machine learning. He has published more than 40 research publication; His research is the area of watermarking. He has been a reviewer of various research journals. He has around 9 years of teaching and research experience. He has guided 25 capstone projects and 15 dissertation.

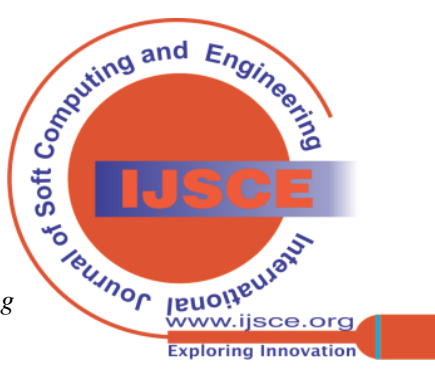

